\title{
PENERAPAN ALGORITMA FUZZY C-MEANS MENGGUNAKAN MODEL RFM DALAM KLASTERISASI PELANGGAN PADA TOKO KUE FEANDRA CAKE
}

\author{
Moh. Azlan Shah Putra ${ }^{1}$, Julhandri ${ }^{2}$, Ihsan Khoiru ${ }^{3}$, Siti Monalisa ${ }^{4}$ \\ Jurusan Sistem Informasi, Universitas Islam Negeri Sultan Syarif Kasim Riau Jl. HR. Soebrantas No. 155 \\ Simpang Baru, Tampan. Pekanbaru, Riau - Indonesia 28293 \\ Email: shah.azlan299@gmail.com, julhandriamin07@gmail.com, ihsankhoiru1997@gmail.com, \\ siti.monalisa@uin-suska.ac.id
}

\begin{abstract}
ABSTRAK
Konsumen merupakan aset yang sangat penting bagi perusahaan yang harus dijaga dengan baik terutama pelanggan potensial. Tujuan proses segmentasi pasar yaitu untuk mengetahui perilaku konsumen serta menerapkan strategi pemasaran yang tepat sehingga mendapatkan keuntungan / profit bagi perusahaan. Objek yang diambil dari penelitian ini yaitu Toko Kue Feandra Cake yang berlokasi Jalan Lobak No. 97, Pekanbaru. Penentuan pelanggan potensial yang dilakukan selama ini adalah secara manual, hanya berdasarkan perkiraan saja tanpa adanya data dan informasi yang pasti. Penelitian ini bertujuan menghasilkan nilai Customer Lifetime Value (CLV) pada setiap segmen pelanggan Feandra Cake dengan menggunakan Algoritma Fuzzy C-Means dalam melakukan klasterisasi pelanggan menggunakan model RFM (Recency, Frequency dan Monetary). Nilai CLV akan dihasilkan dengan mengalikan nilai normalisasi RFM dengan nilai bobot RFM dan selanjutnya dijumlahkan. Hasil dari penjumlahan tersebut didapatkan hasil rangking CLV. Rangking CLV tertinggi dihasilkan dari nilai CLV terbesar diantara 3 kluster tersebut. Rangking CLV tertinggi pada penelitian ini adalah pelanggan pada klaster 1 yang merupakan segmen pelanggan berupa loyalitas yang tinggi dengan nilai Recency yang rendah, Frequency yang tinggi dan Monetary yang tinggi. Ini berarti pelanggan yang berada pada segmen ini sering melakukan pembelian dengan jumlah uang yang dikeluarkan tinggi untuk perusahaan sehingga segmen ini dikatakan pelanggan dengan profitabilitas yang tinggi. Setelah didapatkan klasterisasi pelanggan, selanjutnya dilakukan asosiasi data produk yang dibeli oleh pelanggan menggunakan Algoritma FP-Growth. Hal ini dilakukan untuk mendapatkan kombinasi item pembelian. Produk Suke Ori dan Suke Rasa tidak terdapat dalam hasil asosiasi produk karena merupakan produk andalan Feandra Cake yang sudah pasti pernah dibeli oleh pelangganpelanggannya.
\end{abstract}

Kata kunci: Pelanggan, Fuzzy C-Means, Recency, Frequency dan Monetary (RFM), Customer Lifetime Value(CLV), Klasterisasi, Association Rule, FP-Growth, CRM

\section{A. PENDAHULUAN}

Persaingan usaha yang ketat dewasa ini mengharuskan perusahaan untuk berfokus kepada kebutuhan yang diinginkan oleh konsumen[1]. Pelanggan merupakan aset penting dalam perusahaan yang harus dijaga dengan baik terutama pelanggan potensial. Menurut Chai dan Chan dijelaskan bahwa permasalahan yang sering dihadapi pemasar adalah kesulitan dalam mengidentifikasi pelanggan yang tepat, sehinggan menyebabkan perusahaan dapat kehilangan pelanggan potensial yang akan merugikan perusahaan itu sendiri[2]. Hal ini juga berlaku pada Toko Kue Feandra Cake yang mengalami kesulitan dalam menentukan Pelanggan yang potensial. Feandra Cake merupakan toko kue yang khasnya menjual kue bolu dan susu kedelai yang berlokasi Jalan Lobak No. 97, Pekanbaru.
Penentuan pelanggan potensial yang dilakukan selama ini adalah secara manual, hanya berdasarkan perkiraan saja tanpa adanya data dan informasi yang pasti. Untuk dapat menentukan pelanggan yang potensial, maka Feandra Cake membutuhkan suatu metode untuk mengidentifikasi dan mengelompokkan pelanggan potensial menjadi beberapa cluster atau kelompok dengan meningkatkan pemahaman perusahaan akan kebutuhan mereka sebagai individu sehingga dapat mempertahankan loyalitasnya terhadap perusahaan. Dengan menerapkan konsep CRM (Customer Relationship Management), perusahaan dapat melakukan identifikasi pelanggan dengan melakukan segmentasi pelanggan. Tujuan dari proses segmentasi pelanggan adalah untuk mengetahui perilaku pelanggan dan menerapkan strategi pemasaran yang tepat sehingga mendatangkan keuntungan bagi pihak perusahaan[3]. Segmentasi pelanggan digunakan untuk mengukur nilai pelanggan (Customer Value) 
sehingga perusahaan bisa menentukan pelanggan mana yang memberikan keuntungan yang besar dan mana pelanggan yang tidak memberikan keuntungan[4].

Dalam menentukan kelompok (cluster) yang sesuai dengan pelanggan Feandra Cake, pelanggan dinilai menguntungkan terhadap suatu perusahaan dilihat dari transaksi yang telah dilakukan dengan menggunakan model RFM (Recency, Frequency, dan Monetary). Model RFM merupakan model untuk menentukan segmentasi konsumen berdasarkan kapan transaksi terakhir dilakukan, frequency yaitu tingkat keseringan pelanggan transaksi dan monetary ialah besarnya nilai transaksi yang dilakukan[5].

Segmentasi pelanggan biasanya dilakukan dengan algoritma $K$-Means[4], namun pada penelitian ini akan digunakan algoritma Fuzzy $C$ Means (FCM). Penggunaan algoritma FCM pada penelitian ini dilakukan karena algoritma FCM memiliki nilai entrophy lebih kecil daripada algoritma K-Means, sedangkan nilai purity dari algoritma FCM lebih baik daripada algoritma $K$ Means[6].

\section{B. LANDASAN TEORI}

\section{B.1. Data Mining}

Data Mining adalah proses yang menggunakan teknik statistik, perhitungan, kecerdasan buatan dan machine learning untuk mengekstraksi dan mengidentifikasi informasi yang bermanfaat dan pengetahuan yang terkait dari berbagai basis data besar[7]. Data Mining bukanlah suatu bidang yang sama sekali baru. Dalam aplikasinya, Data Mining sebenarnya merupakan bagian dari proses Knowledge Discovery in Database (KDD), bukan sebagai teknologi yang utuh dan berdiri sendiri[8].

Data mining ditujukan untuk mengekstrak (mengambil intisari) pengetahuan dari sekumpulan data sehingga didapatkan struktur yang dapat dimengerti manusia serta meliputi basis data dan managemen data, prapemrosesan data, pertimbangan model dan inferensi, ukuran ketertarikan, pertimbangan kompleksitas, prapemrosesan terhadap struktur yang ditemukan, visualisasi, dan online updating[8].

\section{B.2. Customer Relationship Management}

Customer Relationship Management (CRM) yaitu suatu rangkaian aktifitas sistematik yang terkelola sebagai usaha untuk semakin mengerti, menarik perhattian konsumen, dan mempertahan kankesetiaan pelanggan yang menguntungkan (most profitable customer) demi mencapai peerkembangan perusahaan yang pesat. Dengan kata lain, CRM bukan dilihat sebagai layanan atau produk, melainkan sebuah filosofi bisnis yang mempunyai tujuan untuk mengoptimalkan nilai pelanggan dalam jangka lama(customer lifetime value)[8].

Dari sisi komunikasi dan manajemen,CRM didefinisikan sebagai sebuah pendekatan perusahaan untuk memahami dan mempengaruhi perilaku konsumen melalui komunikasi yang intensif dalam rangka meningkatkan akuisisi konsumen, mempertahankan konsumen, dan loyalitas konsumen[5].

\section{B.3. Model RFM}

Model RFM ini diperkenalkan pertama kali oleh Arthur Huges dan telah banyak digunakan oleh industri manufaktur, retailer dan industri jasa[4]. Model RFM melibatkan 3 variabel yaitu[9]:

a. Recency adalah jarak dari waktu transaksi terakhir kali dilakukan dengan waktu saat ini. Semakin kecil nilai jarak waktu, maka semakin besar nilai R.

b. Frequency adalah total jumlah transaksi yang dilakukan selama periode tertentu. Semakin besar jumlah transaksi, maka semakin besar nilai $\mathrm{F}$.

c. Monetary adalah total nilai produk dalam bentuk uang dalam periode tertentu. Semakin besar nilai produk, maka semakin besar nilai $\mathrm{M}$.

\section{B.4. Normalisasi RFM}

Melakukan normalisasi data disebabkan selisih data R,F dan $M$ yang sangat jauh sehingga perlu dilakukan normalisasi dengan metode min-max. Persamaan metode min-max sebagai berikut:

$$
\text { Rumus: } \quad A_{N}=\frac{A-\min ^{A}}{\max ^{A}-\min ^{A}}
$$

Dimana :

- $A_{N}=$ Normalisasi Objek Data

- $\mathrm{A}=$ Objek Data

- $\quad \min ^{A}=$ Nilai terkecil dari atribut yang akan di normalisasikan

- $\quad \max ^{A}=$ Nilai terbesar dari atribut yang akan di normalisasikan 


\section{B.5. Algoritma Fuzzy C-Means (FCM)}

FCM adalah adalah algoritma clustering dimana satu objek dapat menjadi anggota beberapa cluster serta batasan cluster FCM adalah samar. Konsep dasar dari FCM pertama kali adalah menentukan pusat dari cluster. Dan setiap titik data memiliki derajat keanggotaan untuk tiap-tiap cluster, Nilai derajat keanggotaan dalam algoritma FCM adalah antara 0 sampai 1[1].

Pada konsep Fuzzy C-Means pertama kali dengan menentukan pusat clusternya, pusat cluster ini yang akan menjadi lokasi rata-rata untuk tiap-tiap cluster. Pada tiap-tiap titik data mempunyai nilai derajat keanggotaan masing-masing, hal ini menandai bahwa tiap data tidak memiliki nilai yang akurat. Agar data mempunyai nilai yang akurat, maka derajat keanggotaan akan terus berukang mendekati nilai minimum tertentu sampai ditemukan nilai akhir yang akurat diantara titik datanya. Pada perulangan ini didasarkan pada meminimalisasi fungsi objektif yang mempertontonkan jarak dari titik data yang diberikan kepusat cluster yang dititik beratkan pada derajat keanggotaan titik data tersebut[8].

\section{B.6. Kaidah Aturan Asosiasi}

Langkah awal dalam melakukan rekomendasi produk adalah menghimpun seluruh informasi mengenai histori pembelian produk oleh pelanggan, meliputi semua pola kombinasi produk yang telah dibeli oleh setiap pelanggan. Salah satu teknik penggalian data yang handal untuk mengetahui pola tersebut adalah analisis asosiasi (association rule mining) untuk menemukan aturan asosiatif antara suatu kombinasi item[10]. Semua data transaksi pelanggan pada pembelian masa lalu dikelompokkan ke dalam klaster.

\section{B.7 Algoritma Frequent Pattern Growth}

Algoritma Frequent Pattern Growth (FPGrowth) adalah pengembangan algoritma Apriori dari teknik penggalian aturan asosiasi yang sering digunakan dalam menemukan aturan asosiatif suatu kombinasi item. FP-Growth menggunakan pendekatan yang berbeda dari paradigma yang digunakan oleh algoritma apriori. Pada algoritma apriori, diperlukan himpunan kandidat untuk mendapatkan data yang paling sering muncul. Sedangkan pada algoritma FP-Growth, menggunakan konsep perluasan pohon prefix yang biasa disebut FP-tree (frequent pattern tree) dalam pencarian himpunan data yang paling sering muncul. FP-Growth dapat langsung mengekstrak himpunan data yang paling sering muncul dari $F P$ tree yang terbentuk menggunakan prinsip divide and conquer[10].

\section{HASIL DAN PEMBAHASAN \\ C.1 Normalisasi Data}

Data yang digunakan pada penelitian ini sebanyak 50 data pelanggam yang berjumlah 330 record dengan periode analisis 1 Agustus 2019 sampai 30 November 2019 yang dapat dilihat pada tabel 1. Dari data tersebut maka akan dipilih data yang memiliki atribut R, F dan M yang dapat dilihat pada tabel 3. Selanjutnya akan dicari nilai minimal dan maksimal dari masing-masing variabel $R, F$ dan M, dapat dilihat pada tabel 2 .

Tabel 1. Data Pembeian Pelanggan

\begin{tabular}{|c|c|c|c|}
\hline No. & Nama & Tanggal & Transaksi \\
\hline \multirow[t]{7}{*}{1} & Insyirah & $24 / 10 / 2019$ & 370.000 \\
\hline & & $20 / 10 / 2019$ & 265.000 \\
\hline & & $17 / 10 / 2019$ & 380.000 \\
\hline & & $16 / 10 / 2019$ & 420.000 \\
\hline & & $14 / 10 / 2019$ & 880.000 \\
\hline & & $12 / 10 / 2019$ & 330.000 \\
\hline & & $10 / 10 / 2019$ & 420.000 \\
\hline \multirow[t]{5}{*}{2} & Jingga & $03 / 11 / 2019$ & 278.000 \\
\hline & & $27 / 10 / 2019$ & 260.000 \\
\hline & & $18 / 10 / 2019$ & 236.000 \\
\hline & & $10 / 10 / 2019$ & 185.000 \\
\hline & & $02 / 10 / 2019$ & 255.000 \\
\hline \multirow[t]{8}{*}{3} & Bunga & & \\
\hline & Rinjani & $26 / 10 / 2019$ & 455.000 \\
\hline & & $18 / 10 / 2019$ & 826.000 \\
\hline & & $14 / 10 / 2019$ & 485.000 \\
\hline & & 07/10/2019 & 1.120 .000 \\
\hline & & 01/10/2019 & 760.000 \\
\hline & & $30 / 09 / 2019$ & 516.000 \\
\hline & & 27/09/2019 & 380.000 \\
\hline \multirow[t]{5}{*}{4} & Dapur Emak & & \\
\hline & Super & $09 / 10 / 2019$ & 70.000 \\
\hline & & $05 / 10 / 2019$ & 70.000 \\
\hline & & 28/09/2019 & 50.000 \\
\hline & & $15 / 09 / 2019$ & 70.000 \\
\hline \multirow[t]{3}{*}{5} & Green Salad & $15 / 10 / 2019$ & 320.000 \\
\hline & & $04 / 10 / 2019$ & 260.000 \\
\hline & & 27/09/2019 & 85.000 \\
\hline$\ldots$ & $\begin{array}{c}\cdots \cdots \\
\text { Atieh Kuni }\end{array}$ & $\begin{array}{c}\ldots \ldots \\
06 / 08 / 2019\end{array}$ & 122000 \\
\hline 50 & Atjen Kup1 & $00 / 08 / 2019$ & 122.000 \\
\hline
\end{tabular}

Tabel 2. Hasil Penilaian Min-Max Pada Model RFM

\begin{tabular}{lllc}
\hline $\begin{array}{c}\text { Variabel } \\
\text { RFM }\end{array}$ & \multicolumn{1}{c}{ Min } & \multicolumn{1}{c}{ Max } & Rata-Rata \\
\hline Recency & 0 & 118 & 45,28 \\
Frekuensi & 1 & 20 & 6,58 \\
Monetary & 116.000 & 9.017 .000 & 1.839 .780 \\
\hline
\end{tabular}


Setelah mengetahui nilai minimal dan maksimal dari masing masing variabel $\mathrm{R}, \mathrm{F}$ dan $\mathrm{M}$ maka persamaan (1), (2) dan (3) akan digunakan untuk mendapatkan normalisasi data setiap pelanggan sesuai dengan variabel $R, F$ dan $M$. Tabel 2 merupakan hasil normalisasi RFM. Nilai normalisasi $\mathrm{R}$, F dan $\mathrm{M}$ dilambangkan dengan $\mathrm{R}_{\mathrm{N}}, \mathrm{F}_{\mathrm{N}}$ dan $\mathrm{M}_{\mathrm{N}}$ pada tabel 3 .

Tabel 3. Data Normalisasi Pembobotan RFM

\begin{tabular}{|c|c|c|c|c|c|c|c|}
\hline No. & Pelanggan & $\mathrm{R}$ & $\mathbf{R}_{\mathbf{N}}$ & $\mathrm{F}$ & $\mathbf{F}_{\mathrm{N}}$ & $\mathrm{M}$ & $\mathbf{M}_{\mathrm{N}}$ \\
\hline 1 & Insyirah & 37 & 0,313559 & 20 & 1 & $\operatorname{Rp} 8.548 .000$ & 0,947309 \\
\hline 2 & Jingga & 27 & 0,228814 & 14 & 0,684211 & Rp 3.427.000 & 0,371981 \\
\hline 3 & Bunga Rinjani & 35 & 0,29661 & 13 & 0,631579 & Rp 9.017.000 & 1 \\
\hline 4 & Dapur Emak Super & 52 & 0,440678 & 10 & 0,473684 & $\mathrm{Rp} \quad 620.000$ & 0,056623 \\
\hline 5 & Mas Ari & 33 & 0,279661 & 8 & 0,368421 & $\operatorname{Rp} 4.985 .000$ & 0,547017 \\
\hline 6 & Maya & 35 & 0,29661 & 9 & 0,421053 & Rp 3.962 .000 & 0,432086 \\
\hline 7 & Green Salad & 46 & 0,389831 & 10 & 0,473684 & $\operatorname{Rp} 2.630 .000$ & 0,28244 \\
\hline 8 & Gerai Shalwa & 57 & 0,483051 & 10 & 0,473684 & Rp 1.998 .000 & 0,211437 \\
\hline 9 & Gerai Salsabila & 54 & 0,457627 & 9 & 0,421053 & $\operatorname{Rp} 3.892 .000$ & 0,424222 \\
\hline 10 & Hanania & 57 & 0,483051 & 8 & 0,368421 & $\operatorname{Rp} 2.890 .000$ & 0,31165 \\
\hline 11 & Gerai Hits Pku & 50 & 0,423729 & 11 & 0,526316 & Rp 5.506.000 & 0,60555 \\
\hline 12 & Toya Green Tea & 45 & 0,381356 & 11 & 0,526316 & $\operatorname{Rp} 2.480 .000$ & 0,265588 \\
\hline 13 & Gerai Thania & 56 & 0,474576 & 9 & 0,421053 & $\mathrm{Rp} 1.102 .000$ & 0,110774 \\
\hline 14 & Gerai Ananda & 52 & 0,440678 & 7 & 0,315789 & $\operatorname{Rp} 2.038 .000$ & 0,215931 \\
\hline 50 & Atjeh Kupi & 10 & 0,084746 & 7 & 0,315789 & Rp 1.805 .000 & 0,189754 \\
\hline
\end{tabular}

\section{C.2 Perangkingan Kluster}

Setelah semua data dinormalisasikan maka selanjutnya akan dilakukan penentuan pengklusteran pelanggan menggunakan Program RapidMiner dengan Teknik klasterisasi FCM, maka didapatkan hasil seperti pada Tabel 4.

Tabel 4. Hasil Klasterisasi RFM

\begin{tabular}{lccc}
\hline \multicolumn{1}{c}{ Klaster } & $\mathrm{R}$ & $\mathrm{F}$ & $\mathrm{M}$ \\
\hline Klaster 1 & 0,386 & 0,316 & 0,205 \\
Klaster 2 & 0,400 & 0,261 & 0,176 \\
Klaster 3 & 0,367 & 0,303 & 0,198 \\
\hline
\end{tabular}

Kluster yang telah dihasilkan tersebut akan dikalikan dengan bobot nilai RFM menggunakan metode pembobotan AHP (Analytical Hierarchy Process). Dalam hal ini, peneliti menggunakan bobot yang sama dengan penelitian (Parvaneh, Abbasimehr and Tarokh, 2012) dengan nilai $W_{R}$, $\mathrm{W}_{\mathrm{F}}, \mathrm{W}_{\mathrm{M}}$ yaitu 0.088, 0.326, dan 0.348. Bobot ini digunakan karena setiap perusahaan memiliki pendapat masing-masing mengenai prioritas pada setiap atribut R, F dan M. setelah dikalikan dengan pembobotan AHP, maka selanjutnya akan menghasilkan peringkat klaster Customer Life Value (CLV) yang dapat dilihat pada Tabel 5.

Tabel 5. Hasil Perangkingan CLV Pelanggan

\begin{tabular}{llllllc}
\hline Klaster & \multicolumn{1}{c}{$\begin{array}{c}\text { Jumlah } \\
\text { Pelanggan }\end{array}$} & R*WR & F*WF & M*WM & CLV & $\begin{array}{c}\text { Rangking } \\
\text { CLV }\end{array}$ \\
\hline 1 & 18 & 0,03397 & 0,10302 & 0,07134 & 0,20832 & 1 \\
2 & 19 & 0,0352 & 0,08509 & 0,06125 & 0,18153 & 3 \\
3 & 13 & 0,0323 & 0,09878 & 0,0689 & 0,19998 & 2 \\
Rata-Rata & & 0,03382 & 0,09563 & 0,06716 & 0,19661 & \\
\hline
\end{tabular}


Dari tabel diatas dapat diambil kesimpulan bahwa kluster 1 mempunyai nilai CLV yang paling tinggi, hal ini berarti bahwa pelanggan yang berada di kluster 1 merupakan pelanggan-pelanggan yang paling loyal dibandingkan pelanggan yang berada di kluster 2 dan 3.

\section{C.3. Asosiasi Produk}

Asosiasi atau rekomendasi produk diambil dari riwayat data pembelian dari setiap pelanggan, yang mana data tersebut akan diolah dan menghasilkan kombinasi item atau aturan asosiatif. Data asosiasi pembelian produk oleh pelanggan, dapat dilihat pada perklasternya padat Tabel 6, 7 dan 8 .

Tabel 6. Data Asosiasi Pelanggan Klaster 1

\begin{tabular}{lcccccccc}
\hline Customer & 1 & 2 & 3 & 4 & 5 & 6 &.. & 18 \\
\hline Suke ori & 1 & 1 & 1 & 1 & 1 & 1 &.. & 1 \\
Suke rasa & 1 & 1 & 1 & 1 & 1 & 1 &.. & 1 \\
Bolu & 0 & 1 & 0 & 0 & 1 & 1 &.. & 0 \\
Bolu topping & 1 & 0 & 1 & 0 & 0 & 0 &.. & 0 \\
Bolu durian & 1 & 0 & 1 & 0 & 0 & 0 &.. & 1 \\
Dessert & 1 & 0 & 1 & 0 & 1 & 0 &.. & 0 \\
Talam & 0 & 0 & 0 & 0 & 1 & 0 &.. & 0 \\
Teh botol & 0 & 1 & 1 & 1 & 0 & 0 &.. & 0 \\
Es doger & 0 & 1 & 0 & 0 & 1 & 1 &.. & 1 \\
Es mangga & 0 & 0 & 0 & 0 & 1 & 0 &.. & 1 \\
Thai tea & 0 & 0 & 0 & 0 & 1 & 0 &.. & 0 \\
Donat & 0 & 0 & 0 & 0 & 1 & 1 &.. & 0 \\
Brownis & 1 & 0 & 1 & 0 & 1 & 0 &.. & 0 \\
\hline
\end{tabular}

Tabel 7. Data Asosiasi Pelanggan Klaster 2

\begin{tabular}{lcccccccc}
\hline Customer & 1 & 2 & 3 & 4 & 5 & 6 &.. & 19 \\
\hline Suke ori & 1 & 1 & 1 & 1 & 1 & 1 &.. & 1 \\
Suke rasa & 1 & 1 & 1 & 1 & 1 & 1 &.. & 1 \\
Bolu & 0 & 0 & 0 & 1 & 0 & 1 &.. & 0 \\
Bolu topping & 0 & 0 & 1 & 0 & 0 & 1 &.. & 0 \\
Bolu durian & 0 & 0 & 0 & 0 & 0 & 0 &.. & 1 \\
Dessert & 0 & 1 & 0 & 1 & 1 & 1 &.. & 0 \\
Talam & 1 & 0 & 0 & 0 & 0 & 0 &.. & 0 \\
Teh botol & 0 & 0 & 0 & 1 & 0 & 0 &.. & 0 \\
Es doger & 0 & 0 & 0 & 1 & 0 & 0 &.. & 1 \\
Es mangga & 0 & 0 & 1 & 0 & 0 & 0 &.. & 1 \\
Thai tea & 0 & 0 & 0 & 0 & 0 & 0 &.. & 0 \\
Donat & 0 & 0 & 1 & 0 & 0 & 0 &.. & 0 \\
Brownis & 0 & 1 & 0 & 0 & 1 & 0 &.. & 0 \\
\hline & & & & & & & &
\end{tabular}

Tabel 8. Data Asosiasi Pelanggan Klaster 3

\begin{tabular}{lrrrrrrrr}
\hline Customer & 1 & 2 & 3 & 4 & 5 & 6 &.. & 13 \\
\hline Suke ori & 1 & 1 & 1 & 1 & 1 & 1 &.. & 1 \\
Suke rasa & 1 & 1 & 1 & 1 & 1 & 1 &.. & 1 \\
Bolu & 1 & 0 & 0 & 1 & 0 & 1 &.. & 1 \\
Bolu topping & 0 & 1 & 0 & 0 & 0 & 0 &.. & 0 \\
Bolu durian & 1 & 0 & 0 & 0 & 1 & 0 &.. & 0 \\
Dessert & 0 & 0 & 1 & 1 & 0 & 0 &.. & 0 \\
\hline
\end{tabular}

\begin{tabular}{lllllllll}
\hline Talam & 0 & 1 & 0 & 0 & 0 & 1 &.. & 0 \\
Teh botol & 1 & 1 & 0 & 1 & 0 & 0 &.. & 0 \\
Es doger & 0 & 0 & 0 & 0 & 0 & 0 &.. & 0 \\
Es mangga & 0 & 0 & 0 & 0 & 0 & 0 &.. & 0 \\
Thai tea & 0 & 0 & 0 & 0 & 0 & 0 &.. & 1 \\
Donat & 0 & 0 & 0 & 0 & 0 & 0 &.. & 1 \\
Brownis & 0 & 0 & 0 & 0 & 0 & 0 &.. & 0 \\
\hline
\end{tabular}

Selanjutnya data pembelian produk diolah menggunakan Program Rapidminer dengan Algoritma FP-Growth untuk mendapatkan pola kombinasi produk yang dibeli pelanggan. Hasil asosiasi data pembelian masing-masing klaster yang didapatkan dapat dilihat pada Tabel 9, 10 dan 11.

Tabel 9. Hasil Asosiasi Data Pelanggan 1

\begin{tabular}{ll}
\hline Premises & Conclusion \\
\hline brownis, teh botol & bolu topping \\
bolu durian, dessert & brownis \\
brownis, teh botol & bolu durian \\
bolu durian, teh botol & brownis \\
dessert, bolu & brownis \\
brownis, es doger & dessert \\
dessert, es doger & brownis \\
bolu durian, teh botol & bolu topping \\
dessert, bolu & bolu topping \\
dessert, teh botol & bolu topping \\
bolu topping, bolu & brownis \\
durian, dessert & \\
brownis, teh botol & bolu topping, bolu \\
& durian \\
brownis, bolu topping, & bolu durian \\
teh botol & \\
bolu durian, teh botol & brownis, bolu topping \\
brownis, bolu durian, & bolu topping \\
teh botol & \\
bolu topping, bolu & brownis \\
durian, teh botol & \\
dessert, bolu & brownis, bolu topping \\
brownis, dessert, bolu & bolu topping \\
\hline
\end{tabular}

Tabel 10. Hasil Asosiasi Data Pelanggan 2

\begin{tabular}{ll}
\hline Premises & Conclusion \\
\hline dessert & talam \\
bolu topping & talam \\
\hline
\end{tabular}

Tabel 11. Hasil Asosiasi Data Pelanggan 3

\begin{tabular}{ll}
\hline Premises & Conclusion \\
\hline dessert & bolu durian \\
bolu topping & bolu durian \\
Talam & bolu durian \\
\hline
\end{tabular}

\section{KESIMPULAN}

Implementasi Metode Clustering dengan Algoritma Fuzzy C-Means menghasilkan segmen pelanggan dengan nilai CLV yang tertinggi yaitu 
klaster 1. pelanggan pada klaster 1 merupakan segmen pelanggan berupa loyalitas yang tinggi dengan nilai Recency yang rendah, Frequency yang tinggi dan Monetary yang tinggi. Ini berarti pelanggan yang berada pada segmen ini sering melakukan pembelian dengan jumlah uang yang dikeluarkan tinggi untuk perusahaan sehingga segmen ini dikatakan pelanggan dengan profitabilitas yang tinggi. Oleh karena itu pelanggan pada segmen ini perlu dipertahankan dengan memberikan layanan yang terbaik agar mereka tidak menjadi target pemasaran bagi pesaing.

Asosiasi pembelian produk oleh pelanggan menghasilkan cross-selling dalam banyak kemungkinan pada klaster 1, seperti bolu durian, brownis, bolu topping dan dessert. Hal ini disebabkan karena banyaknya produk yang dibeli oleh pelanggan pada klaster 1 . Sedangkan pada klaster 2 menghasilkan cross-selling dengan produk talam. Dan pada klaster 3 menghasilkan crossselling dengan produk bolu durian. Suke Ori dan Suke Rasa tidak terdapat dalam hasil rekomendasi produk karena merupakan produk andalan Feandra Cake yang sudah pasti pernah dibeli oleh pelangganpelanggannya.

\section{E. DAFTAR PUSTAKA}

[1] D. Astria and Suprayogi, "Penerapan Algoritma Fuzzy C-Means Untuk Clustering Pelanggan Pada CV. Mataram Jaya Bawen," pp. 169-178, 2017.

[2] E. Muningsih, "Penerapan Metode Fuzzy CMeans dengan Model Fuzzy RFM (Studi Kasus: Clustering Pelanggan Potensial Online Shop)," pp. 157-161, 2015.

[3] T. Kristanto and R. Arief, "Analisa Data Mining Metode Fuzzy Untuk Customer Relationship Management pada Perusahaan Tour \& Travel," vol. d, no. 2009, pp. 2-4, 2013.
[4] S. Monalisa, "Segmentasi Perilaku Pembelian Pelanggan Berdasarkan Model RFM dengan Metode K-Means," vol. 5341, no. April, pp. 9-15, 2018.

[5] F. Hadi, D. O. Rahmadia, F. H. Nugraha, N. P. Bulan, Mustakim, and S. Monalisa, "Penerapan K-Means Clustering Berdasarkan RFM Mofek Sebagai Pemetaan dan Pendukung Strategi Pengelolaan Pelanggan ( Studi Kasus: PT . Herbal Penawar Alwahidah Indonesia Pekanbaru )," vol. 15, no. 1, pp. 69-76, 2017.

[6] A. R. Virgiawan, "Segmentasi Pelanggan Menggunakan Analisis RFM dan Algoritman Fuzzy C-Means Untuk Membantu Pengelolaan Hubungan Pelanggan pada PT. XYZ,” 2015.

[7] S. Yohanni, Yusnidah, and A. Beni, "Penerapan Algoritma Fuzzy C-Means Dipadukan Dengan Model Fuzzy Recency Frequency Monetary (RFM) Untuk Customer Relationship Management (CRM) (Studi Kasus Di Toko Sweet Amirah Medan)," pp. 7-16, 2014.

[8] N. R. Syarif and Windarto, "Aplikasi Data Mining Dengan Menggunakan Algoritma Fuzzy C-Means dan Metode Recency Frequency Monetary ( RFM ) Untuk Pengelompokan Pelanggan pada PT Eka Cipta Rasa," vol. 1, no. 3, pp. 1093-1099, 2018.

[9] D. B. Saputra and E. Riksakomara, "Implementasi Fuzzy C-Means dan Model RFM untuk Segmentasi Pelanggan (Studi Kasus : PT. XYZ)," vol. 7, no. 1, pp. 1-6, 2018.

[10] D. Kurniawaty, A. Djunaidy, and R. P. Kusumawardani, "Rekomendasi Produk Berdasarkan Loyalitas Pelanggan Menggunakan Integrasi Metode AHP dan Teknik Penggalian Data : Studi Kasus CV . XYZ," no. September, 2014. 